\title{
Sequential auctions with synergies: the paradox of positive synergies
}

\author{
Citation for published version (APA):
}

Leufkens, K., Peeters, R. J. A. P., \& Vermeulen, A. J. (2010). Sequential auctions with synergies: the paradox of positive synergies. METEOR, Maastricht University School of Business and Economics. METEOR Research Memorandum No. 007 https://doi.org/10.26481/umamet.2010007

Document status and date:

Published: 01/01/2010

DOI:

10.26481/umamet.2010007

Document Version:

Publisher's PDF, also known as Version of record

\section{Please check the document version of this publication:}

- A submitted manuscript is the version of the article upon submission and before peer-review. There can be important differences between the submitted version and the official published version of record.

People interested in the research are advised to contact the author for the final version of the publication, or visit the DOI to the publisher's website.

- The final author version and the galley proof are versions of the publication after peer review.

- The final published version features the final layout of the paper including the volume, issue and page numbers.

Link to publication

\footnotetext{
General rights rights.

- You may freely distribute the URL identifying the publication in the public portal. please follow below link for the End User Agreement:

www.umlib.nl/taverne-license

Take down policy

If you believe that this document breaches copyright please contact us at:

repository@maastrichtuniversity.nl

providing details and we will investigate your claim.
}

Copyright and moral rights for the publications made accessible in the public portal are retained by the authors and/or other copyright owners and it is a condition of accessing publications that users recognise and abide by the legal requirements associated with these

- Users may download and print one copy of any publication from the public portal for the purpose of private study or research.

- You may not further distribute the material or use it for any profit-making activity or commercial gain

If the publication is distributed under the terms of Article $25 \mathrm{fa}$ of the Dutch Copyright Act, indicated by the "Taverne" license above, 


\section{Maastricht University}

Kasper Leufkens, Ronald Peeters, Dries Vermeulen

Sequential auctions with synergies: The paradox of positive synergies

RM/ 10/007

\section{METEOR}

Maastricht University School of Business and Economics

Maastricht Research School of Economics

of Technology and Organization

P.O. Box 616

NL - 6200 MD Maastricht

The Netherlands 


\title{
Sequential auctions with synergies: The paradox of positive synergies *
}

\author{
Kasper Leufkens ${ }^{\dagger} \quad$ Ronald Peeters ${ }^{\ddagger} \quad$ Dries Vermeulen ${ }^{\S}$
}

February 26, 2010

\begin{abstract}
We show that synergies enhance bidding competition to such an extent that they are a curse rather than a blessing for the bidders; they may even induce serious bankruptcy problems.

JEL Classification: D44; H57.

Keywords: Sequential auctions; Procurement auctions; Synergies; Bankruptcy; Declining price anomaly.
\end{abstract}

\section{Introduction}

A distinguishing characteristic of procurement auctions is their sequential nature: auctions take place one after the other with time intervals between them. Construction contracts, military procurement and the uncoordinated sequence of European spectrum auctions during 2000 and 2001 are examples of such sequential settings. Bidders may experience synergies (cost benefits) by winning multiple contracts. These synergies can be material, for instance owning specialized equipment, or intangible, such as expertise.

There is ample empirical evidence that presence of synergies affects bidding behavior and auction outcomes (cf. Hendricks and Porter, 1988; Ausubel et al., 1997; De Silva, 2005). Cramton (2002) argues that one reason for the enormous revenue in the spectrum auction by the United Kingdom is that it was the first in the sequence of UMTS auctions throughout Europe (see also Van Damme, 2002). Winners in the UK auction were well positioned for subsequent auctions and hence bidders could view it as a foot-in-the-door to Europe.

\footnotetext{
${ }^{*}$ We would like to thank conference participants in Atlanta (IIOC 2005), Maastricht (SING 2005), Amsterdam (NAKE Research Day 2005) and Boston (IIOC 2006) for useful comments.

${ }^{\dagger}$ Department of Economics, Maastricht University, P.O. Box 616, 6200 MD Maastricht, The Netherlands.

${ }^{\ddagger}$ Corresponding author. Department of Economics, Maastricht University, P.O. Box 616, 6200 MD Maastricht, The Netherlands. Email: R.Peeters@algec.unimaas.nl. The author gratefully acknowledges financial support by the Dutch Science Foundation (NWO).

${ }^{\S}$ Department of Quantitative Economics, Maastricht University, P.O. Box 616, 6200 MD Maastricht, The Netherlands. Email: D.Vermeulen@ke.unimaas.nl.
} 
The theoretical literature on sequential auctions with synergies has mainly focused on revenues and price trends. Branco (1997) and Jeitschko and Wolfstetter (2002) have shown that synergies may induce a declining price trend and higher revenues for the auctioneer, which appears positive for, for instance, government procurement. In addition to the consequences for efficiency and prices, we focus on the impact of positive synergies on the bidders' payoffs. We analyze a sequential auction of two stochastically equivalent objects with positive synergies and show that synergies are a curse rather than a blessing for bidders. Even in equilibrium, bidders may face serious losses, and hence, bankruptcy problems. The negative economic consequences caused by these bankruptcy problems are of importance for auction design when synergies are present.

\section{Model and equilibrium}

We consider a private value auction with $n \geq 2$ risk neutral bidders. Two stochastically equivalent objects are auctioned sequentially using the second-price sealed-bid format. Bidders' valuations are distributed according to the differentiable cumulative distribution function $F(v)$ with associated density function $f(v)$ on the interval $[0, \infty)$. In particular, $F(0)=0, F$ is non-decreasing, and $\lim _{v \rightarrow \infty} F(v)=1$. We assume that the expected valuation is finite, thus $\mathbb{E}(v)=\int_{0}^{\infty} v f(v) \mathrm{d} v<\infty$. Valuations are individually uncorrelated, drawn independently from the same identical distribution at the start of each auction, and private information.

Although no bidder knows his valuation for the second object during the first auction, it is common knowledge that winning the first auction increases this valuation by a factor $s>1$. This synergy factor only applies to the valuation for the second object, $v_{2}$. Winning the first auction then increases the second auction valuation from $v_{2}$ to $s v_{2}$, but does not have any effect on the first auction valuation $v_{1}$. Prior to the second auction, bidders learn whether they won the first auction or not.

We write $b_{k i}$ and $v_{k i}$ for respectively the bid and valuation in auction $k=1,2$ of bidder $i=1, \ldots, n$. In the second auction the winner of the first auction is denoted by $w$ and bidder $\ell$ refers to one of the $n-1$ bidders that did not win the first auction. Because of symmetry, we only have three different expected payoffs. By $\bar{\pi}_{1 i}$ we denote the expected payoff for bidder $i$ in the first auction, prior to the realization of the valuations for this auction. By $\bar{\pi}_{2 w}\left(\bar{\pi}_{2 \ell}\right)$ we denote the expected second auction payoff of the winner (a loser) of the first auction, prior to the realization of the valuations for the second auction. The expected price of auction $k, \bar{p}_{k}$, is also prior to the realization of the valuations and thus precisely the seller's expected revenue of that auction. The seller's expected total revenue from the auction sequence is denoted by $\bar{R}$ and the expected total payoff for bidder $i$ is denoted by $\bar{\mu}_{i}$.

Proposition 1. The bidding strategies given by

$$
b_{1 i}^{*}=v_{1 i}+\Delta \quad \text { with } \quad \Delta=\bar{\pi}_{2 w}-\bar{\pi}_{2 \ell}
$$


and

$$
b_{2 i}^{*}= \begin{cases}v_{2 i} & \text { if the first auction is lost } \\ s v_{2 i} & \text { if the first auction is won }\end{cases}
$$

constitute a symmetric linear subgame perfect Bayesian Nash equilibrium.

In the second auction, the bidders bid their true (synergy-adjusted) valuation. In the first auction all bidders mark up their stand-alone valuation in the first auction with the difference in expected payoff between entering the second auction as a winner and a loser. We refer to this mark-up as the option value of winning the first auction.

\section{The impact of synergies}

In this section the impact of synergies on bidding behavior and economic performance is investigated. For the latter, we devote attention to respectively the bidders' expected payoffs, the probability by which losses are incurred, the seller's revenue, and the induced price trend.

The first proposition learns that the synergy factor has a positive impact on the option value and hence on competitiveness of bidding behavior in the first auction.

Proposition 2. (i) $\lim _{s \downarrow 1} \Delta=0$; (ii) $\frac{\mathrm{d} \Delta}{\mathrm{d} s}>0$; (iii) $\lim _{s \rightarrow \infty} \Delta=\infty$.

Since all bidders upgrade their bid with a factor equal to the option value, they forego the full potential benefit of entering the second auction as a winner already in competition for this option value. Hence, the ex ante expected total payoff equals the sum of the expected payoff of a single auction without synergies and the expected payoff in the second auction when being a loser in the first auction: $\bar{\mu}=\bar{\pi}+\bar{\pi}_{2 \ell}$. This latter factor is decreasing in the synergy factor since the probability to win decreases while the expected price to pay in case of a win increases. The following proposition shows that the ex ante expected total payoff of the bidders converges to the expected payoff of a single auction without synergies when the synergy grows large.

Proposition 3. (i) $\lim _{s \downarrow 1} \bar{\mu}=2 \cdot \bar{\pi}$; (ii) $\frac{\mathrm{d} \bar{\mu}}{\mathrm{d} s}<0$; (iii) $\lim _{s \rightarrow \infty} \bar{\mu}=\bar{\pi}$.

It is well known that (part of) a possible rent is dissipated during the competition for that rent. However, in our model not only the possible rent is completely dissipated, bidders are even worse off than in a setting without synergies. When the synergies are large, bidders have half the ex ante expected total payoff they would have if there were no synergies. Given the fact that the total surplus that is divided between the seller and the bidders is larger with than without synergies, this observation is surprising. Instead of benefiting from the presence of synergies bidders suffer from it. Positive synergies form a paradox in this setting in the sense that bidders actually suffer from the presence of positive synergies, instead of having benefit from them. 
The uncertainty concerning the benefits from synergies leads to an exposure problem in the sequential auction. Bidders bid above their valuation in the first auction, and consequently it is possible that the instantaneous payoff of the first auction is negative. The winner of the first auction may not win the second auction, or win it but still not recover the loss of the first auction. The total payoff of the sequential auction as a whole is then negative.

Let $P(s)$ denote the ex ante probability that the winner of the first auction makes a loss when the synergy factor is $s$.

Proposition 4. For all $\varepsilon>0$ there is $\bar{s}$ such that $P(s) \geq \mathbb{P}\{v<\mathbb{E}(v)\}-\varepsilon$ for all $s>\bar{s}$.

Roughly, this proposition states that, for large synergy factors $s$, the probability that the winner of the first auction makes a loss is at least $\mathbb{P}\{v<\mathbb{E}(v)\}$. Thus, the loss effect is particularly severe for distributions where a bidder has a high probability of a relatively low valuation, and a rather small probability to have an extremely high valuation, since this guarantees the situation where a majority of the values is below the expected value.

In any case, the ex ante expected total payoff of the sequential auction is, of course, nonnegative for bidders. Therefore, the losses that bidders can make in equilibrium are not a major concern when these bidders enter many similar settings. However, large projects are typically not auctioned regularly. Spectrum auctions, special military procurement, and large building projects are all examples of this. In such a setting, losses made on one project can hardly be recovered and bankruptcy problems are likely to occur.

The expected price in the first auction equals the sum of the expected price of a single auction without synergies and the option value: $\bar{p}_{1}=\bar{p}+\Delta$. Consequently, the expected price in the first auction is increasing in the synergy factor. In the second auction, the synergy has an increasing effect on valuations and thus the expected price. Hence, the seller's expected revenue, $\bar{R}=\bar{p}_{1}+\bar{p}_{2}$, is increasing in the synergy factor.

Proposition 5. (i) $\lim _{s \downarrow 1} \bar{R}=2 \cdot \bar{p}$; (ii) $\frac{\mathrm{d} \bar{R}}{\mathrm{~d} s}>0$.

The increase in the revenue of the seller is not only due to the increased surplus that is divided. The seller also captures a part of the payoffs bidders originally had. The gain from synergies for the seller is therefore more than the value of the synergies itself.

There is ample empirical evidence of declining price trends in sequential auctions (Ashenfelter, 1989; Ashenfelter and Genesove, 1992; Beggs and Greddy, 1997). Branco (1997) was the first to attribute the declining price anomaly to the presence of positive synergies, a theoretical finding that was extended to heterogenous objects by Jeitschko and Wolfstetter (2002). For heterogeneous objects with discrete valuations Tang Sørensen (2006), on the other hand, shows that prices can both be increasing or decreasing.

Proposition 6. $\bar{p}_{1}>\bar{p}_{2} \Longleftrightarrow \int_{0}^{\infty} f(v) \int_{v}^{s v}\left[(n-1) F^{n-1}(x)-(n-2) F^{n-2}(x)\right] \mathrm{d} x \mathrm{~d} v>0$; There exists an $\bar{s}$ such that $\bar{p}_{1}>\bar{p}_{2}$ for all $s>\bar{s}$. 
In case of uniformly distributed valuations, prices are unambiguously declining. However, declining prices are in general not guaranteed. ${ }^{1}$ Nevertheless, for any distribution function and number of bidders declining prices are found if the synergy factor is sufficiently large, as the last proposition states.

Although the sequential auction is ad interim efficient for any synergy factor, ex post inefficiencies may occur due to the fact that the first auction may select a socially undesirable winner; something that does not occur in absence of synergies. This ex post efficiency is caused by the uncertainty about the private valuations in the second auction during the first auction. When the synergies become large, the probability of an ex post inefficient allocation converges to $\frac{n-1}{n}$. Then an ex post efficient allocation is only attained if the bidder that wins the first auction draws the highest valuation in the second auction.

\section{Concluding remarks}

Another auction environment where winners are known to be 'cursed' is the common value auction. The option value in our setting may appear as a common value component in the first auction. Despite the similarities in appearance, the two values are different. For common value auctions the true value of the object is equal for all bidders but their information on it differs. The option value in our setting is, in general, different for the bidders, though they possess identical information on it prior to the auctioning.

Our findings indicate that, in presence of possible synergies, it may be profitable for the auctioneer to announce future auctions well in advance. However, a transparent procurement policy can be a two-edged sword. The winner of the first auction can make a loss and consequently go bankrupt. Especially for large governmental procurement projects this can be a severe problem.

\section{References}

1. Ashenfelter, O. (1989). How auctions work for wine and art. Journal of Economic Perspectives, 3 (3), 23-36.

2. Ashenfelter, O. and D. Genesove (1992). Testing for price anomalies in real-estate auctions. American Economic Review, 82 (2), 501-505.

3. Ausubel, L., P. Cramton, R.P. McAfee, and J. McMillan (1997). Synergies in wireless telephony: Evidence from the broadband PCS auctions. Journal of Economics and Management Strategy, 6 (3), 497-527.

4. Beggs, A. and K. Graddy (1997). Declining values and the afternoon effect: Evidence from art auctions, RAND Journal of Economics, 28 (3), 544-565.

\footnotetext{
${ }^{1}$ Appendix $\mathrm{C}$ provides an example where an increasing price trend is observed.
} 
5. Branco, F. (1997). Sequential auctions with synergies: An example. Economics Letters, $54(2), 159-163$.

6. Cramton, P. (2002). Spectrum auctions. In: Cave, M., S. Majumdar, and I. Vogelsang Handbook of telecommunications economics. Amsterdam: Elsevier 605-639.

7. De Silva, D.G. (2005). Synergies in recurring procurement auctions: An empirical investigation. Economic Inquiry, 43 (1), 55-66.

8. Damme, E. van (2002). The European UMTS-Auctions. European Economic Review, 46 (4-5), 846-869.

9. Hendricks, K. and R. Porter (1988). An empirical study of an auction with asymmetric information. American Economic Review, 78 (5), 865-883.

10. Jeitschko, T.D. and E. Wolfstetter (2002). Scale economies and the dynamics of recurring auctions. Economic Inquiry, 40 (3), 403-414.

11. Tang Sørensen, S. (2006). Sequential auctions for stochastically equivalent complementary objects. Economics Letters, 91 (3), 337-342. 


\section{A Expressions}

In this section we will provide explicit expressions for the expected payoffs and prices. Furthermore, we will give three useful expressions for $\Delta$.

\section{A.1 Expected payoffs}

In the first auction all bidders are symmetric. Without synergies $(s=1)$ the expected instantaneous payoff of each auction is given by

$$
\bar{\pi}=\int_{0}^{\infty} v F^{n-1}(v) f(v) \mathrm{d} v-(n-1) \int_{0}^{\infty} v F^{n-2}(v) f(v)(1-F(v)) \mathrm{d} v .
$$

When synergies are present, so $s>1$, the expected instantaneous payoff for a bidder $i$ is then given by

$$
\bar{\pi}_{1}=\int_{0}^{\infty} v F^{n-1}(v) f(v) \mathrm{d} v-(n-1) \int_{0}^{\infty}(v+\Delta) F^{n-2}(v) f(v)(1-F(v)) \mathrm{d} v .
$$

The bidder of type $w$ wins the second auction if his synergy-adjusted bid is higher than that of all the other bidders and the price he has to pay is determined by the highest bid among the $n-1$ bidders of type $\ell$. Thus the expected instantaneous second auction payoff for the winner of the first auction is given by

$$
\bar{\pi}_{2 w}=\int_{0}^{\infty} s v F^{n-1}(s v) f(v) \mathrm{d} v-(n-1) \int_{0}^{\infty} v F^{n-2}(v) f(v)(1-F(v / s)) \mathrm{d} v .
$$

A bidder of type $\ell$ only wins if his bid is above that of all other losers and the bid of bidder $w$. There are two possibilities to consider for the expected instantaneous second auction price a bidder of type $\ell$ has to pay; one of the remaining $n-2$ bidders of type $\ell$ has the second highest bid (third term) or bidder $w$ has the second highest bid (second term). Thus the expected instantaneous second auction payoff for a loser is given by

$$
\begin{aligned}
\bar{\pi}_{2 \ell}=\int_{0}^{\infty} & v F^{n-2}(v) F(v / s) f(v) \mathrm{d} v-\int_{0}^{\infty} s v F^{n-2}(s v) f(v)(1-F(s v)) \mathrm{d} v \\
& -(n-2) \int_{0}^{\infty} v F^{n-3}(v) F(v / s) f(v)(1-F(v)) \mathrm{d} v .
\end{aligned}
$$

A bidder's ex ante expected total payoff of the auction sequence is given by

$$
\bar{\mu}_{i}=\bar{\pi}_{1 i}+\frac{1}{n} \bar{\pi}_{2 w}+\frac{n-1}{n} \bar{\pi}_{2 \ell} .
$$

This follows from the fact that all bidders are symmetric ex ante and hence bidder $i$ wins the first auction with probability $\frac{1}{n}$.

The first auction winner pays, besides the price he would pay if there was only a single auction, the difference in the expected payoff of the second auction between winning and losing the first auction. This means that the ex ante expected total payoff, $\bar{\mu}$, of the auction sequence as a whole equals the expected instantaneous payoff of a single auction without synergies, $\bar{\pi}$, plus the expected payoff in the second auction when the first auction has been lost:

$$
\bar{\mu}=\bar{\pi}_{1 i}+\frac{1}{n} \bar{\pi}_{2 w}+\frac{n-1}{n} \bar{\pi}_{2 \ell}=\bar{\pi}-\frac{1}{n}\left(\bar{\pi}_{2 w}-\bar{\pi}_{2 \ell}\right)+\frac{1}{n} \bar{\pi}_{2 w}+\frac{n-1}{n} \bar{\pi}_{2 \ell}=\bar{\pi}+\bar{\pi}_{2 \ell} .
$$




\section{A.2 Option value}

Since $\Delta=\bar{\pi}_{2 w}-\bar{\pi}_{2 \ell}$, we can substitute the above formulas for $\bar{\pi}_{2 w}$ and $\bar{\pi}_{2 \ell}$. The result can be rewritten to

$$
\begin{aligned}
\Delta=s \int_{0}^{\infty} & v F^{n-2}(s v) f(v) \mathrm{d} v+(n-2) \int_{0}^{\infty} v f(v) F^{n-3}(v) F(v / s) \mathrm{d} v \\
& -(n-1) \int_{0}^{\infty} v f(v) F^{n-2}(v) \mathrm{d} v
\end{aligned}
$$

or alternatively

$$
\begin{aligned}
\Delta=s \int_{0}^{\infty} & v F^{n-2}(s v) f(v) \mathrm{d} v-(n-2) \int_{0}^{\infty} v f(v) F^{n-3}(v)(F(v)-F(v / s)) \mathrm{d} v \\
& -\int_{0}^{\infty} v f(v) F^{n-2}(v) \mathrm{d} v .
\end{aligned}
$$

We focus on the second term of this latter expression for $\Delta$. This term can be rewritten as follows.

$$
\begin{aligned}
(n- & 2) \int_{0}^{\infty} v f(v) F^{n-3}(v)(F(v)-F(v / s)) \mathrm{d} v=(n-2) \int_{0}^{\infty} v f(v) F^{n-3}(v) \int_{v / s}^{v} f(x) \mathrm{d} x \mathrm{~d} v \\
& =(n-2) \int_{0}^{\infty} \int_{v / s}^{v} v f(v) F^{n-3}(v) f(x) \mathrm{d} x \mathrm{~d} v=(n-2) \int_{0}^{\infty} \int_{x}^{s x} v f(v) F^{n-3}(v) f(x) \mathrm{d} v \mathrm{~d} x \\
& =(n-2) \int_{0}^{\infty} f(x) \int_{x}^{s x} v f(v) F^{n-3}(v) \mathrm{d} v \mathrm{~d} x=\int_{0}^{\infty} f(x) \int_{x}^{s x} v \mathrm{~d} F^{n-2}(v) \mathrm{d} x \\
& =\int_{0}^{\infty} f(x)\left[s x F^{n-2}(s x)-x F^{n-2}(x)-\int_{x}^{s x} F^{n-2}(v) \mathrm{d} v\right] \mathrm{d} x \\
& =\int_{0}^{\infty} f(x) s x F^{n-2}(s x) \mathrm{d} x-\int_{0}^{\infty} f(x) x F^{n-2}(x) \mathrm{d} x-\int_{0}^{\infty} f(x) \int_{x}^{s x} F^{n-2}(v) \mathrm{d} v \mathrm{~d} x .
\end{aligned}
$$

Plugging this back into the expression for $\Delta$ and canceling equal terms yields

$$
\Delta=\int_{0}^{\infty} f(x) \int_{x}^{s x} F^{n-2}(v) \mathrm{d} v \mathrm{~d} x .
$$

\section{A.3 Prices}

In our setting all bidders increase their first auction bids with the aim of obtaining an advantage for the second auction. The only change in the bids of the second auction is the increased bid of the participant of type $w$. Therefore, it can be that the expected price is higher in the first auction than in the second auction. The expected price for the first object equals the expected second highest valuation plus $\Delta$. The expected price in the second auction is the sum of the expected payments made by each of the $n-1$ bidders of type $\ell$ and the single bidder of type $w$. The expected prices in both auctions are then

$$
\bar{p}_{1}=n(n-1) \int_{0}^{\infty}(v+\Delta) F^{n-2}(v) f(v)(1-F(v)) \mathrm{d} v
$$


and

$$
\begin{aligned}
& \bar{p}_{2}=(n-1) \int_{0}^{\infty} v F^{n-2}(v) f(v)(1-F(v / s)) \mathrm{d} v \\
&+(n-1)\left\{\int_{0}^{\infty} s v F^{n-2}(s v) f(v)(1-F(s v)) \mathrm{d} v\right. \\
&\left.\quad+(n-2) \int_{0}^{\infty} v F^{n-3}(v) F(v / s) f(v)(1-F(v)) \mathrm{d} v\right\} .
\end{aligned}
$$

\section{B The impact of synergies}

Proof of Proposition 2 The third expression for $\Delta$ in Appendix A reads

$$
\Delta=\int_{0}^{\infty} f(x) \int_{x}^{s x} F^{n-2}(v) \mathrm{d} v \mathrm{~d} x .
$$

This expression is strictly increasing in $s$. Moreover, it is clear that $\Delta=0$ for $s=1$.

For the limiting behavior, we separately analyze the three terms in the first expression for $\Delta$ from Appendix A. Regarding the first integral, define the function $G:[0, \infty) \rightarrow[0, \infty)$ by

$$
G(v)= \begin{cases}0 & \text { if } v=0 \\ v f(v) & \text { else. }\end{cases}
$$

Since $F(0)=0$, and for any $v>0$ the value $s v$ becomes large when $s$ becomes large, it can be seen that $v F^{n-2}(s v) f(v)$ is non-decreasing in $s$ and converges pointwise to $G$ as $s \rightarrow \infty$. Thus, by Lebesgue's Theorem of Monotone Convergence, we know that

$$
\int_{0}^{\infty} v F^{n-2}(s v) f(v) \mathrm{d} v \rightarrow \int_{0}^{\infty} G(v) \mathrm{d} v=\mathbb{E}(v) \text { as } s \rightarrow \infty .
$$

Regarding the second integral, recall that $F$ is continuous, non-decreasing, and $F(0)=0$. Thus, $f(v) F^{n-3}(v) F(v / s) \downarrow 0$ pointwise as $s \rightarrow \infty$. Hence,

$$
\int_{0}^{\infty} v f(v) F^{n-3}(v) F(v / s) \mathrm{d} v \rightarrow 0 \text { as } s \rightarrow \infty .
$$

Finally observe that the third integral does not depend on $s$. The result now follows.

Proof of Proposition 3 It is easily seen from the expressions in Appendix A that $\bar{\pi}_{2 \ell}=\bar{\pi}$ for $s=1$.

For each loser in the first auction the probability of winning the second auction is decreasing in $s$. In addition, the expected price to pay in case the second auction is won is increasing in $s$. Given that the own valuation is not affected by a change in $s$, it follows that the expected payoff $\bar{\pi}_{2 \ell}$ is decreasing in $s$.

From Appendix A we know that

$$
\begin{aligned}
\bar{\pi}_{2 \ell}= & \int_{0}^{\infty} v F^{n-2}(v) F(v / s) f(v) \mathrm{d} v-\int_{0}^{\infty} s v F^{n-2}(s v) f(v)(1-F(s v)) \mathrm{d} v \\
& \quad-(n-2) \int_{0}^{\infty} v F^{n-3}(v) F(v / s) f(v)(1-F(v)) \mathrm{d} v \\
\leq & \int_{0}^{\infty} v F^{n-2}(v) F(v / s) f(v) \mathrm{d} v .
\end{aligned}
$$


Since $\bar{\pi}_{2 \ell} \geq 0$, and the latter expression converges to zero as $s \rightarrow \infty$ by Lebesgue's Monotone Convergence Theorem, we obtain that $\bar{\pi}_{2 \ell} \rightarrow 0$ as $s \rightarrow \infty$.

Proof of Proposition 4 Notice that, due to the bidding strategies, the winner of the first auction pays at least $\Delta$. Now, suppose that bidder $i$ won the first auction. When the realization of valuations for bidder $i$ is $\left(v_{1 i}, v_{2 i}\right)$ and $v_{1 i}+s v_{2 i}<\Delta$, bidder $i$ certainly makes a loss, no matter whether he wins or loses the second auction. Thus,

$$
P(s) \geq \mathbb{P}\left[v_{1 i}+s v_{2 i}<\Delta \mid i \text { wins the first auction }\right] .
$$

Consequently, it suffices to show that, given $\varepsilon>0$,

$$
\mathbb{P}\left[\frac{v_{1 i}}{s}+v_{2 i}<\frac{\Delta}{s} \mid i \text { wins the first auction }\right] \geq \mathbb{P}[v<\mathbb{E}(v)]-\varepsilon
$$

for $s$ sufficiently high. Take $\varepsilon>0$. Since $\lim _{v \rightarrow \infty} F(v)=1$ we can take $V>0$ such that $F(V)>1-\varepsilon$. Then, $\mathbb{P}\left[v_{1 i}<V\right] \geq 1-\varepsilon$. Take $\bar{s}$ such that, for all $s>\bar{s}, \frac{V}{s}<\varepsilon$ and $\Delta-\frac{V}{s} \geq \mathbb{E}(v)-\varepsilon$. Then for $s>\bar{s}$,

$$
\begin{aligned}
\mathbb{P}\left[\frac{v_{1 i}}{s}+\right. & \left.v_{2 i}<\frac{\Delta}{s} \mid i \text { wins }\right] \\
= & \mathbb{P}\left[v_{1 i} \geq V\right] \cdot \mathbb{P}\left[\frac{v_{1 i}}{s}+v_{2 i}<\frac{\Delta}{s} \mid i \text { wins, } v_{1 i} \geq V\right] \\
& \quad+\mathbb{P}\left[v_{1 i}<V\right] \cdot \mathbb{P}\left[\frac{v_{1 i}}{s}+v_{2 i}<\frac{\Delta}{s} \mid i \text { wins, } v_{1 i}<V\right] \\
\geq & (1-\varepsilon) \cdot \mathbb{P}\left[\frac{v_{1 i}}{s}+v_{2 i}<\frac{\Delta}{s} \mid i \text { wins, } v_{1 i}<V\right] \\
\geq & (1-\varepsilon) \cdot \mathbb{P}\left[\frac{V}{s}+v_{2 i}<\frac{\Delta}{s} \mid i \text { wins, } v_{1 i}<V\right] \\
= & (1-\varepsilon) \cdot \mathbb{P}\left[v_{2 i}<\frac{\Delta-V}{s} \mid i \text { wins, } v_{1 i}<V\right] \\
= & (1-\varepsilon) \cdot \mathbb{P}\left[v<\frac{\Delta-V}{s}\right] \\
\geq & (1-\varepsilon) \cdot \mathbb{P}[v<\mathbb{E}(v)-\varepsilon] .
\end{aligned}
$$

The proof is complete once we observe that the probability $\mathbb{P}[v<\mathbb{E}(v)-\varepsilon]$ converges to $\mathbb{P}[v<\mathbb{E}(v)]$ as $\varepsilon \rightarrow 0$.

Proof of Proposition 5 From the expressions in Appendix A it is easily seen that $\bar{p}_{1}=$ $\bar{p}_{2}=\bar{p}$ for $s=1$.

The increase of $\bar{p}_{1}$ in $s$ follows directly from $\Delta$ being increasing in $s$. The vector of synergy-adjusted values in the second auction is increasing in $s$. From this it follows that the second-highest synergy-adjusted value is nondecreasing in $s$, though strictly increasing in expectation. Since the expected price in the second auction $\bar{p}_{2}$ is precisely the expected second-highest synergy-adjusted value, it follows that $\bar{p}_{2}$ is strictly increasing in $s$.

Proof of Proposition 6 From Proposition 2 it follows that $\bar{p}_{1}$ diverges as $s \rightarrow \infty$. However, for any synergy factor $s, \bar{p}_{2}$ is smaller than or equal to the expected value of the highest valuation in the single auction without synergies, that is, the expected value of the random variable 
$\max _{i}\left\{v_{i}\right\}$. To see this, observe that, for any realization $\left(v_{21}, \ldots, v_{2 n}\right)$ in the second auction, in case the winner of the first auction wins the second auction, we have $p_{2} \leq \max _{i}\left\{v_{2 i}\right\}$ and also in case another bidder, say $j$, wins the second auction we have $p_{2} \leq \max _{i}\left\{v_{2 i}\right\}$, because $p_{2} \leq v_{2 j}$. Finally, recall that in our model $\mathbb{E}(v)<\infty$. Now, the above statement follows from the observation that $\mathbb{E}\left(\max _{i}\left\{v_{i}\right\}\right) \leq n \mathbb{E}(v)$.

\section{Examples}

In this section we illustrate our findings by means of three examples. First, we present the typical example of valuations being uniformly drawn from the unit interval. Next, the second example considers a (trivial) case where there are no losses possible, even though the synergy induces increased competition in the auction for the first object. Finally, we present an example in which an increasing price trend is observed.

\section{C.1 Uniform distribution}

Let for each bidder the valuation be a random draw from the interval $[0,1]$ according to a uniform distribution. The symmetric linear equilibrium gives then rise to the following specification:

$$
\begin{aligned}
& b_{1 i}^{*}=v_{1 i}+\left(\frac{1}{2} s-\frac{n-1}{n}+\frac{1}{2} \frac{n-2}{n} \frac{1}{s}\right) \quad \bar{\pi}_{1 i}=\frac{1}{n(n+1)}-\frac{1}{n}\left(\frac{1}{2} s-\frac{n-1}{n}+\frac{1}{2} \frac{n-2}{n} \frac{1}{s}\right) \\
& b_{2 i}^{*}=\left\{\begin{array}{ll}
v_{2 i} & \text { if auction } 1 \text { is lost } \\
s v_{2 i} & \text { if auction } 1 \text { is won }
\end{array} \quad \bar{\pi}_{2 i}= \begin{cases}\frac{1}{n(n+1)} \frac{1}{s} & \text { if auction } 1 \text { is lost } \\
\frac{1}{2} s-\frac{n-1}{n}+\frac{1}{2} \frac{n-1}{n+1} \frac{1}{s} & \text { if auction } 1 \text { is won }\end{cases} \right. \\
& \bar{p}_{1}=\frac{n-1}{n+1}+\left(\frac{1}{2} s-\frac{n-1}{n}+\frac{1}{2} \frac{n-2}{n} \frac{1}{s}\right) \quad \bar{\mu}_{i}=\frac{1}{n(n+1)}+\frac{1}{n(n+1)} \frac{1}{s} \\
& \bar{p}_{2}=\frac{n-1}{n}-\frac{n-1}{n(n+1)} \frac{1}{s} \quad \bar{R}=\frac{1}{2} s+\frac{n-1}{n+1}+\frac{1}{2} \frac{n-3}{n+1} \frac{1}{s} .
\end{aligned}
$$

It can easily be verified that the effect of the synergy factor, $s$, on the payoff in the second auction, $\bar{\pi}_{2 i}$, is positive in case the first auction is won, but negative if the first auction is lost. Hence, the option value and the bids in the first auction are increasing in $s$. This implies that the synergy enhances competition in the first auction and the expected payoff in the first auction, $\bar{\pi}_{1 i}$, is consequently decreasing in $s$. Moreover, we see that the overall payoff, $\bar{\mu}_{i}$, is decreasing in $s$, indicating that (in expectation) bidders suffer from the synergy. Both auctions' prices, $\bar{p}_{1}$ and $\bar{p}_{2}$, and consequently the auction revenue, $\bar{R}$, are increasing in $s$. Finally, the first auction's price, $\bar{p}_{1}$, is always larger than the second auction's price, $\bar{p}_{2}$, such that for valuations uniformly distributed over the unit interval, prices are declining.

The payoff in the second auction, $\bar{\pi}_{2 i}$, is decreasing in the number of bidders, $n$, regardless of the outcome of the first auction. The option value, though, is strictly decreasing in $n$. Consequently, the bidding in the first auction becomes less aggressive the more bidders are present. The effect of $n$ on the payoff in the first auction, $\bar{\pi}_{1 i}$, is however ambiguous. For instance, for $s=1.7$ this payoff is decreasing when the number of bidders increases from 3 to 
4, but increasing when the number of bidders increases from 5 to 6 . Despite this ambiguity, the overall payoff, $\bar{\mu}_{i}$, is decreasing in $n$. Where the expected price in the second auction, $\bar{p}_{2}$, is clearly increasing in $n$, this is ambiguous for the price in the first auction, $\bar{p}_{1}$. The derivative of $\bar{p}_{1}$ with respect to $n$ is given by $\frac{\mathrm{d} \bar{p}_{1}}{\mathrm{~d} n}=\frac{2}{(n+1)^{2}}-\left(1-\frac{1}{s}\right) \frac{1}{n^{2}}$ and can be negative as well as positive. For instance, for $s=9$ and $n=2$ the derivative is equal to zero, such that for any lower (larger) $s$ the derivative is positive (negative). Nevertheless, the expected revenue, $\bar{R}$, is unambiguously increasing in $n$. This implies that the increase of $\bar{p}_{2}$ dominates an eventual decrease of $\bar{p}_{1}$.

\section{C.2 No losses}

First, consider the trivial case with each bidder having a value of $v$, such that the winner of the first object will win the second object with certainty. The excess surplus that a win of the first object generates in the auction for the second object is then $\Delta=(s-1) v$. In the first auction all bidders upgrade their truthful bid of $v$ with this option value effect, whereas in the second auction they just bid their value. This guarantees a decreasing price trend $\left(\bar{p}_{1}=s v\right.$ and $\left.\bar{p}_{2}=v\right)$. Moreover, all bidders end up with an overall payoff of 0 . This means that there is no bankruptcy problem and the seller roams off precisely the excess surplus (no more and no less) that is generated by the synergy. All these properties, both qualitatively and quantitatively, are independent of the number of bidders, $n$.

The absence of bankruptcy problems in this example is not driven by the fact that the winner of the first object, wins the second object with certainty. Namely, in case the values are drawn from the interval $[\underline{v}, \bar{v}]$ with $\underline{v}<\bar{v}<s \underline{v}$, the latter property is satisfied whereas bankruptcies may occur. It is precisely the lack of uncertainty about current and future valuations of all bidders, and hence the complete information structure, that guarantees absence of bankruptcies.

\section{C.3 Increasing prices}

Let for each bidder the value be $\bar{v}$ with probability $\theta$ and $\underline{v}$ with probability $1-\theta$ with $\bar{v}>\underline{v}$. Moreover, let the synergy factor be such that $\bar{v}>s \underline{v}$, such that winning the first item does not automatically lead to winning both objects.

The expected prices for the first and second object are given by

$$
\bar{p}_{1}=(1-\theta)^{n} \underline{v}+n \theta(1-\theta)^{n-1} \underline{v}+\left[1-(1-\theta)^{n}-n \theta(1-\theta)^{n-1}\right] \bar{v}+\Delta
$$

and

$$
\bar{p}_{2}=(1-\theta)^{n} \underline{v}+n \theta(1-\theta)^{n-1}\left[\frac{1}{n} \underline{v}+\frac{n-1}{n} s \underline{v}\right]+\left[1-(1-\theta)^{n}-n \theta(1-\theta)^{n-1}\right] \bar{v},
$$

where $\Delta$ indicates the expected benefit from having the synergy and is given by

$$
\begin{aligned}
\Delta & =\theta(1-\theta)^{n-1}[(s \bar{v}-\underline{v})-(s \underline{v}-\underline{v})]+\theta\left[1-(1-\theta)^{n-1}\right](s \bar{v}-\bar{v})+(1-\theta)^{n}(s \underline{v}-\underline{v}) \\
& =\theta(s-1) \bar{v}+(1-\theta)^{n-1}(s-1) \underline{v} .
\end{aligned}
$$


In expectation there is an increasing price trend if $\bar{p}_{2}>\bar{p}_{1}$. This is the case if

$$
s \underline{v}<\bar{v}<(1-\theta)^{n-1}\left[(n-1)-\frac{1}{\theta}\right] \underline{v} .
$$

A configuration for which both these inequalities are satisfied is: $\underline{v}=0.5, \bar{v}=0.6, \theta=0.1$, $n=21$, and $s=1.1$. 